\title{
Enterotoxic, Neurotoxic and Cytotoxic Effects Demonstrated by Shiga Toxin (2d) Producing Escherichia coli in Experimental Models
}

\author{
Ahsan CR*, Begum K, Kabir E, Talukder KA \\ Department of Microbiology, Dhaka University, Dhaka, Bangladesh
}

\begin{abstract}
Background:Shiga toxin (Stx) producing Escherichia coli (STEC) colonise human intestinal tract and their infections have asymptomatic clinical manifestations which cause local and systemic pathological changes.
\end{abstract}

Objectives: This study intended to establish the role of Shiga toxin (Stx2d) in developing clinical manifestations in STEC infections using experimental models.

Methods:A total 300 stool samples were screened from hospitalised diarrhoeal patients enrolled in $2 \%$ surveillance system at International Centre for Diarrhoeal Disease Research, Bangladesh (icddr,b). The $s t x$ gene profile including their variants was identified by PCR.stx $2 d$ gene positive STEC PT187 was selected for toxin (s) preparation.Toxin was prepared by centrifugation of culture supernatant. Enterotoxicand paralytic-lethal activities were tested in rabbit ileal loops and mice, respectively. Histopathological study of the rabbit ileal loop segments and different tissues of mice by paraffin embedded method and stained by $\mathrm{H} \& \mathrm{E}$ staining. Cytotoxic effect was performed on HeLa cells.

Results: Nine STEC strains were identified for $s t x_{2}$ gene positive. Among them STEC PT187 was found $s t x_{2 d}$ gene positive strain and selected for toxic activities. Toxin (s) responsible for causing accumulation of fluid in rabbit ileal loops and its segments showed inflammation and enterocytenecrosis. In mouse model, toxin (s) was found to cause hind limbs paralysis and death. Brain, spinal cord and kidney tissue of mice showed histopathological changes. Toxin (s) also showed positive cytotoxic activity in HeLa cell.

Conclusion:In this study, results indicated that Stx2d producing E. coli exhibit not only enterotoxic activity, but also cause impaired neurological functions and cytotoxic effect.

Keywords: Stx2d, cytotoxic effect, enterotoxic effect, neurotoxic effect

\section{Introduction}

Shiga toxin producing Escherichia coli (STEC) strains have emerged as one of the majorcause of human gastrointestinal diseases resulting in lifethreatening complications such as haemolyticuremic syndrome (HUS) which is the most common cause of acute renal failure in children. In some cases, patients infected by STEC, also showed neurological symptoms. ${ }^{1}$ Epidemiological studies from different parts of the world established STEC as the major cause of watery or bloody diarrhea and HUS, mostly in temperate climatic regions.,3 Domestic animals, mainly cattle, sheep, and goats, have been established as major natural reservoirs for STEC and play a significant role in the epidemiology of human infections. In most of the developing countries, hygienic conditions are severely compromised

*Correspondence: Dr. Chowdhury Rafiqul Ahsan, Departemnt of Microbiology, University of Dhaka, Bangaldesh; e-mail: crahsan@du.ac.bd; ORCID: 0000-0001-5024-6293 and living with domestic animals within the same premises is a common practice. Although the socioeconomic status and living style of the people in South Asian countries including Bangladesh support the prevalence of STEC infections, however, only few studies have been conducted in this region until now. This is probably because the STEC isnot considered as a common pathogen among hospitalized patients in Bangladesh suffering from mild cases of diarrhoea within the community. ${ }^{2}$ On the other hand, development of therapeutic and preventative strategies to combat STEC infections requires a thorough understanding of the mechanisms by which STEC organisms colonize the human intestinal tract and cause local and systemic pathological changes. Pathogenicity of STEC is associated with their ability to produce diverse virulence and toxic factors. The main factors are the ability to produce shiga toxins which can be subdivided into shiga toxin1 (Stx1) and shiga toxin2 (Stx2). Nucleotide sequence 
analysis of the $s t x_{1}$ and $s t x_{2}$ genes revealed the existence of different variants in both groups. So far, three $s t x_{1}$ subtypes $\left(s t x_{1}, s t x_{1 \mathrm{c}}, s t x_{1 \mathrm{~d}}\right)$ and several $s t x_{2}$ variants (e.g. $s t x_{2 \mathrm{c}}, s t x_{2 \mathrm{~d}}, s t x_{2 \mathrm{e}}, s t x_{2 \mathrm{f}}$, $s t x_{2 \mathrm{~g}}$ ) have been described. ${ }^{4-7}$

Among these variants, Stx 2 showed the strongest toxic effects and Stx2d has displayed cytoxicityto Vero cells, which increased by 10-1000 folds. ${ }^{4,8}$ Several studies have shown that the prevalence of strains having $s t x_{2 d}$ gene is present more in livestock reservoirs than in humans. Stx2d was found to be significantly associated with bloody diarrhoea and systemic complications such as HUS. ${ }^{9}$ On the other hand, shigatoxin is also found neurotoxic and destroyed neurons. ${ }^{10}$ However, molecular basis of neuronal damage caused by the shiga toxin has remained unclear. Aim of this study was to investigate the role of shiga toxintype $2 \mathrm{~d}$ produced by E.coli, in producing enterotoxic, neurotoxic and cytotoxic effects using animal models and mammalian cell culture.

\section{Material and Methods}

Isolation and identification of STEC strain: A total of 300 stool specimens collected from icddr,bdiarrhoea treatment centre, under the systematic surveillance system from $2.0 \%$ patients attending at the icddr,b diarrhoea treatment centre, between December 2001 and August 2002, every fifth patient attending the hospital was included for sampling. Stool samples were collected in sterile stool container, were examined for STECstrainisolation. All samples were tested for STECisolation following standard methods, ${ }^{11,12}$ by PCR using $\mathrm{stx}_{1}$ and $\mathrm{stx}_{2}$ primers with their variants. ${ }^{5,6,13-15}$ Isolated STECstrains were reconfirmed for $s t x_{1}, s t x_{2}$ and $s t x_{2}$ variants according to the protocol described. ${ }^{16}$ Isolatedstrains were serologically confirmed by using commercially available antisera kit. Preparation of $\operatorname{toxin}(s)$ :Toxin(s) was prepared following the method described, ${ }^{17,18}$ briefly, strain was grown aerobically at $37^{\circ} \mathrm{C}$ in Trypticase Soy Broth (TSB) for $24 \mathrm{~h}$ and culture was centrifuged $(13,000 \mathrm{~g}$ for $20 \mathrm{~min})$ and supernatant was concentrated $(1 \mathrm{mg} / \mathrm{ml})$ over sucrose. ${ }^{19}$ Concentrated supernatant was filtered through $0.22 \mu \mathrm{m}$ millipore membrane. Protein concentration of the sample was estimated by BioRad protein assay according to Bradford method.

Rabbit ileal loop assay: Enterotoxic effect was performed in New Zealand rabbitsas described by Singh et al,.$^{20} 1 \mathrm{ml}$ of toxin(s) was inoculated into rabbit ileal loops. $V$. cholerae 569B and VTEC were used as positive controls. Sterile TSB was used as negative control. Each test was done using two rabbits. The length of each loop and the volume of fluid accumulated were measured to determine the amount of fluid accumulation per unit length of gut $(\mathrm{ml} / \mathrm{cm})$. After rabbit ileal loop assay,histopathological study of full-thickness segments of the ligated ileum was performed by paraffin embedded method and stained by haematoxylin and eosin (H\&E) staining and examined under light microscope.The histological changes were graded from 0 to $4+$, with 0 (normal) being no change and $4+$ equalling severe inflammation andenterocytic necrosis. ${ }^{21}$

RITARD model test:Ten $\mathrm{ml}$ of cell culture suspension in PBS $\left(3 \times 10^{8} \mathrm{CFU} / \mathrm{ml}\right)$ was injected into the lumen of the anterior jejunum of adult New Zealand rabbits. ${ }^{22}$ Each test was done using two rabbits. Rabbits were observed for signs and symptoms of diarrhoea, weakness and death. Rectal swabs were taken daily and plated onto MacConkey agar to identify shedding of the test organism. Isolated colonies were confirmed by PCR analysis.Ten $\mathrm{ml}$ PBS was injected in duplicate rabbits were used as negative controls.

Mouse lethality test:Five groups of Swiss Albino mice (six per group), 6 to 8 weeks old,were injected intra-peritoneally (IP) with five different doses $(0.1 \mu \mathrm{g}, 1 \mu \mathrm{g}, 5 \mu \mathrm{g}, 10 \mu \mathrm{g}, 50 \mu \mathrm{g}$ per mice $)$ of toxin(s).TSB was used as negative control. Deaths were monitored twice daily and $50.0 \%$ lethal dose $\left(\mathrm{LD}_{50}\right)$ was determined. ${ }^{23}$ Mice were observed for signs of toxic effect until death. Histopathological study of brain, spinal cord and kidney tissues were performed according to the procedures described earlier.

Cytotoxic assay:Cytotoxic effect of toxin(s) in $\mathrm{HeLa}$ cell linewasdetermined. ${ }^{24}$ Morphological alteration of the HeLa cell was observed after staining the actin filaments with fluorescein isothiocyanate (FITC) - conjugated phalloidinunder epifluorescence microscope. ${ }^{25}$

Ethics statement: The $2.0 \%$ surveillance system was a routine ongoing activity of the icddr,b Dhaka Hospital which has been approved by the Research Review Committee (RRC) and Ethical Review Committee (ERC) of icddr,b. Since most of the patients were illiterate, informed oral consent was obtained from the caregivers or guardians on behalf of the patients for collecting stool specimens only, following the hospital policy. The information was stored in the hospital database and used for conducting research. The verbal consent was documented by keeping a checkmark in the questionnaire which was again shown to the patient 
or the guardians. At the same time, patients or the guardians were assured about the non-disclosure of information collected from them, and were also informed about the use of data for analysis and using the results for improving patient

\section{Results}

Isolation and identification of STEC strainsby $P C R$ : Nine strainsout of 300 stoolsamples were identifiedfor STEC specific genest $x_{2}$ (tableI). Among them only one representative STEC(PT187 st $x_{2 d}$ gene positive) strain was selected for this study.This strain was further analysed for serological typing and confirmed to belong to the $\mathrm{O} 2$ serotype.

Induction of fluid accumulation in rabbit ileal loop: Toxin(s) of STEC PT187 caused fluid accumulationin rabbit ileal loops. $V$. cholerae 569B and VTEC were found to cause accumulation of fluid, whileTSB (negative control) did not (figure 1).

Table I: Identification of $s t x_{1}$ and $s t x_{2}$ gene producing $E$. coli by PCR.

\begin{tabular}{lcc}
\hline Sample no & $\boldsymbol{s t x}_{\mathbf{1}}$ gene & st $\boldsymbol{x}_{2}$ gene \\
\hline PT49 & - & + \\
PT92 & - & + \\
PT149 & - & + \\
PT164 & + & + \\
PT187 & - & + \\
PT210 & - & + \\
PT271 & - & + \\
PT277 & - & + \\
PT281 & - & + \\
VTEC3 & + & + \\
K-12 & - & - \\
\hline
\end{tabular}
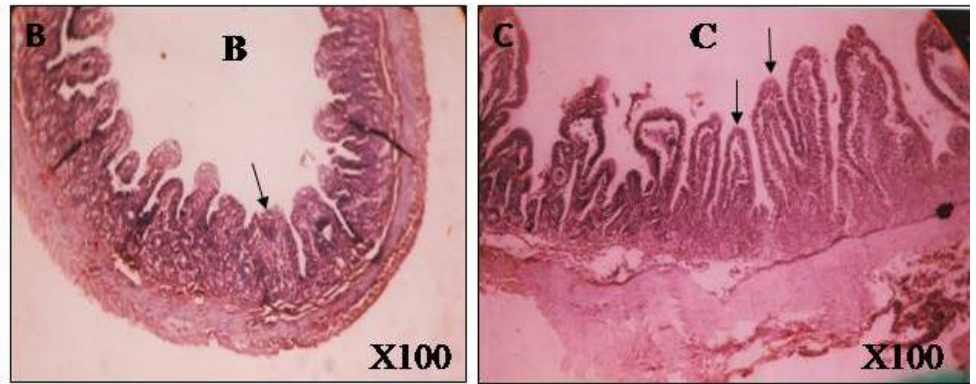

Figure 2: Effect of Stx2d in rabbit ileal loop tissue (stained with H \& E). Section of STEC PT187, V. cholerae 569B and TSB treated rabbit ileal loop A, B, and C, respectively. All photographs were taken at a magnification of x100.

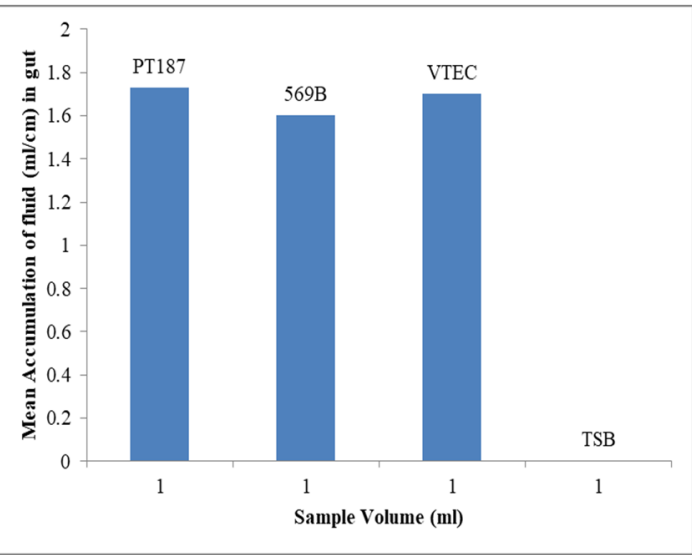

Figure 1: Volume of fluid accumulated in rabbit ileal loops after inoculation of toxin of PT187. 569B V. cholerae and VTEC used as positive controls and TSB as a negative control.

Histological examination: Ileal segments exposed to toxin showed inflammation in mucosa, submucosa and sometimes in the muscle layer. It also revealed enterocytic necrosis and shearing off tip of villi and alteration of villi integrity (Grade-4 inflammation) shown in figure $2 \mathrm{~A}$. The section exposed to enterotoxic $V$. cholerae 569B revealed infiltration of polymorphs in mucosa, submucosa, and muscle layer (Grade-3 inflammation) shown in figure 2B. Villi integrity wasmore or less maintained. No change except mild inflammation was observedin TSB treated loops (figure 2C).
Enterotoxigenic effect by RITARD model:Over a 5-day observation, it was recorded that the rabbit produced mucus containing watery stools within first 24 hours which lasted for 3 days. After five days, an autopsy of the small intestine of rabbits appeared normal.PBS injected rabbits, served as negative controls and did not produce diarrhoeal signs and symptoms.

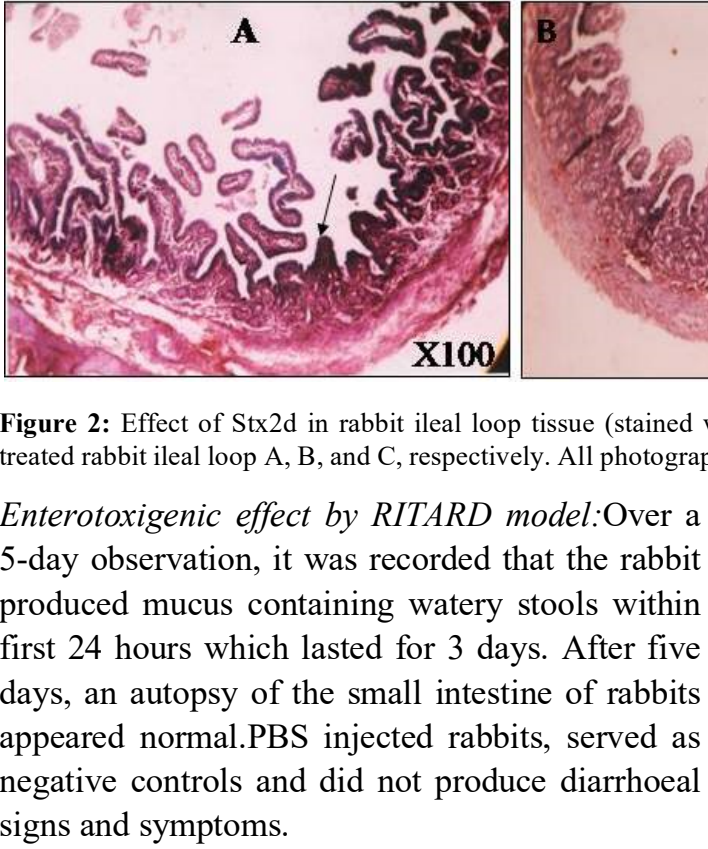

Bangladesh Med Res Counc Bull 2020; 46:41-47
Neurotoxic effect in mice: $\mathrm{LD}_{50}$ dose of Stx $2 \mathrm{~d}$ was found to be $1 \mu \mathrm{g}$ toxin(s). The sign of toxic effect appeared within 36 hours which included ruffled fur, huddling and disinclination to move, when effective dose was given. Hind limb paralysis and rapid breathing were observed as signs of severe illness and all mice died within 48 hours. No signs of toxic effect were observed in TSB injected mice. 
Histological examination: Histological examination of the brain tissue revealed moderate number of congested blood vessels and larger foci of microhaemorrhage (figure 3A1). Spinal cord tissue exhibited moderate number of congested blood vessels, foci of microhaemorrhage and separated cord tissue fragments (figure 3B1).
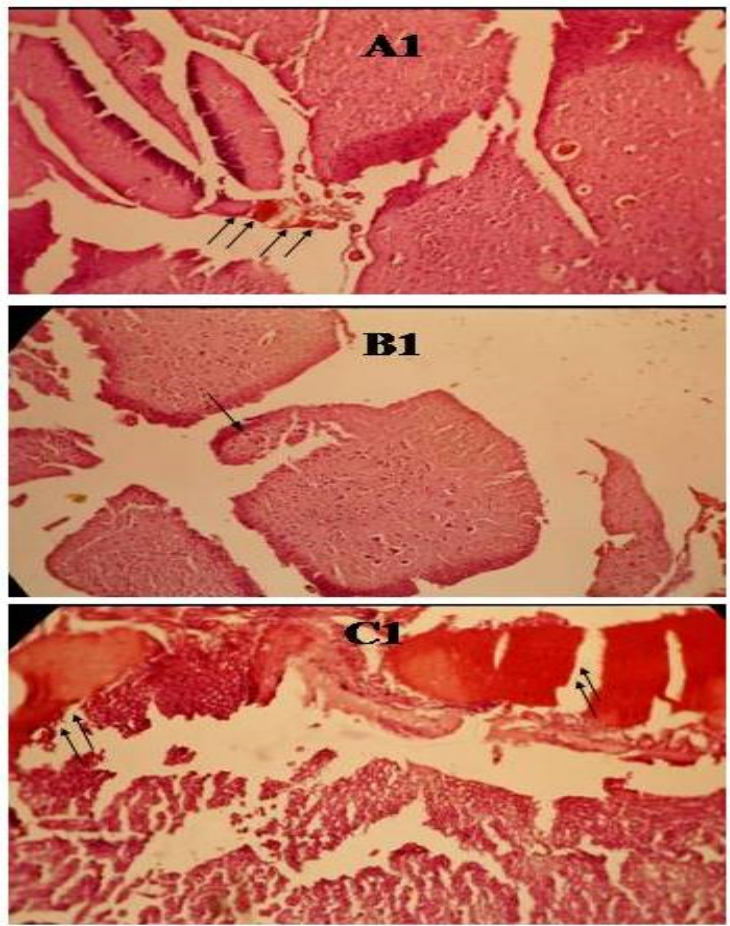

Figure 3: Stx2d caused histopathological changes in mice tissues. Section of STEC PT187 treated brain (A1), spinal cord (B1) and kidney tissue (C1); TSB treated brain (A2), spinal cord (B2) and kidney tissue (C2) showed unremarkable change.All photographs were taken at a magnification of X100.
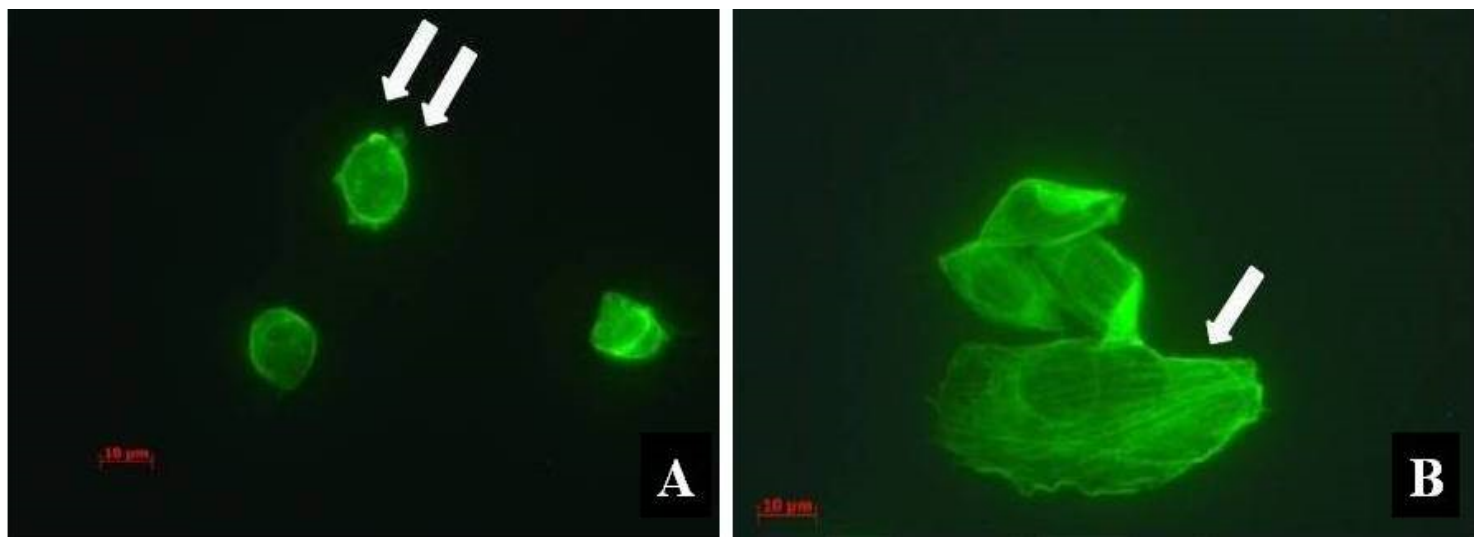

Figure 4: Stx2d caused morphological changes of HeLa cells. (A) treated with Stx2d showing round structure caused by destroying actin filament (double arrow in A), (B) untreated control cells showed normal morphology of cells with actin filament (single arrow in B). All photographs were taken at a magnification of $x 40$.

Cytotoxic effectin HeLa cells:Toxin (s) showed cytotoxic potential by studying the morphological changes underepifluorescence microscope, which after 24 hourswas round due to destructionof actin filament as shown in figure 4A.The untreated cells showed normal morphology with actin filament (figure 4B). 


\section{Discussion}

Patients infected by STEC initially suffer from watery diarrhoea, but in some cases progresses to bloody diarrhoea and haemorrhagic colitis. ${ }^{26-28}$ The roles of particular genotypic variants in human pathogenesis are not clear. However, Stx2d producing strain has been shown to be the strongest among all variants. ${ }^{4}$ In this study, STEC PT187positive for $s t x_{2 d}$ strain was identified from diarrheal patientsand its toxic activities were investigated. Earlier it was reported in 1995 that, STEC infections among the patients with diarrhoea was not identified in Bangladesh. ${ }^{29}$ Studying the pathogenicity of this strain showed that the toxin(s) has ability to induce fluid accumulation in rabbit ileal loop (figure 1) and cause inflammation and alteration of villi integrity(figure 2). Further evidence showed that this toxin produced mucus-producing diarrhoeain the RITARD model test. STEC strains are a diverse group in their capacity to cause serious diseases in humans, and their key determinants of virulence are their ability to adhere to intestinal epithelial cells and colonize the human gut. Previous studies have shown that shiga toxin causes damage to villus cells by destroying absorptive cells and causing net fluid secretion. ${ }^{30}$

Previously, it has been reported that, neurological disorders are the most frequent extra-intestinal manifestations of shigellosis occurring in children as well as in adults. ${ }^{31}$ Convulsions were observed as the most significant neurological symptom of STEC infection. ${ }^{32,33}$ The findings of Richardson et al., displayed disruption of the nerve supply to the limbs causing paralysis. $^{34}$ This coincides withresults from this studywhich showed that the toxin(s) caused hind limb paralysis and damage to nervous tissues within mice model (figure3). Obata and his colleagues also reported that Stx2 causes altered neuronal function leading to paralysis. ${ }^{35}$

Kidney tissue treated with this toxin(s) in mice caused degenerative to necrotic change in the tubular epithelial cells (figure 3). During histopathological observation, damage to the glomerular endothelial cell is referred to as a hallmark of HUS. ${ }^{36}$ STEC infection progressing to HUS, is characterized by a triad of acute renal failure, microangiopathic haemolyticanaemia, and thrombocytopenia. ${ }^{37}$ Some individuals with HUS experienced neurological symptoms including lethargy, severe headache, convulsions, and encephalopathy. ${ }^{38}$ Additionally, the toxin (s) hascytotoxic activity by destroying actin filament in HeLa cell (figure 4). Shiga toxin induced cell death is an important process in the pathophysiological response of humans.

\section{Conclusion}

The present study represents functional studies from $s x_{2 d}$ gene positive strain, STEC (PT187). The Stx $2 \mathrm{~d}$ produced by STEC showed both enterotoxic and neurotoxic activities. The toxin (s) also exhibited strong cytotoxic potential in animal models. Results from the animal model and human cell studies were found to be consistent with clinical abnormalities shown in human STEC infections.

\section{Acknowledgement}

Authors gratefully acknowledge these donors for their support and their commitment to icddr,b's research-based efforts. The funders had no role in study design, data collection and analysis, decision to publish, or preparation of the manuscript.

Conflict of interest: The authors declare no conflict of interest.

Funding: This research study was funded by icddr,b and its donors, which provided unrestricted support to icddr,b for its operations and research. Current donors providing unrestricted support include: Australian Agency for International Development (AusAID), Government of the People's Republic of Bangladesh; Canadian International Development Agency (CIDA), Swedish International Development Cooperation Agency (Sida), and the Department for International Development, UK (DFID).

Submitted: $29^{\text {th }}$ October, 2019

Final revision received: $17^{\text {th }}$ March, 2020

Accepted: $19^{\text {th }}$ March, 2020

Published online: $1^{\text {st }}$ April, 2020

\section{References}

1. Paton AW, Paton JC. Detection and characterization of Shiga toxigenic Escherichia coli by using multiplex PCR assays for stxl, stx2, eaeA, enterohemorrhagic E. coli hlyA, rfbO111, and rfbO157. J. Clin. Microbiol.1998;36:598-602.

2. Islam MA, Heuvelink AE, de Boer E, Sturm PD, Beumer RR, et al. Shiga toxin-producing Escherichia coli isolated from patients with diarrhoea in Bangladesh. J. Med. Microbiol.2007;56:380-85.

3. Tarr PI, Gordon CA, Chandler WL. Shiga toxinproducing Escherichia coli and haemolyticuraemic syndrome. Lancet. 2005;365:1073-86.

4. Melton-Celsa AR, Darnell SC, O'Brien AD. Activation of Shiga-like toxins by mouse and 
human intestinal mucus correlates with virulence of enterohemorrhagicEscherichia coli O91:H21 isolates in orally infected, streptomycin-treated mice. Infect. Immun. 1996;64:1569-76.

5. Pierard D, Muyldermans G, Moriau L, et al. Identification of new verocytotoxin type 2 variant B-subunit genes in human and animal Escherichia coli isolates. J. Clin. Microbiol. 1998;36:3317-22.

6. Schmidt H, Scheef J, Morabito S,Stevens D, Lauwers S, et al. A new Shiga toxin variant (Stx2f) from Escherichia coli isolated from pigeons. Appl. Environ. Microbiol. 2000; 66:1205-08.

7. Kuczius T, Bielaszewska M, Friedrich AW,Zhang $\mathrm{W}$. A rapid method for the discrimination of genes encoding classical Shiga toxin (Stx) 1 and its variants, Stx1c and Stx1d, in Escherichia coli. Mol. Nutr. Food Res. 2004; 48:515-20.

8. Kokai-Kun JF, Melton-Celsa AR,O'Brien AD. Elastase in intestinal mucus enhances the cytotoxicity of Shiga Toxin type 2d. J. Biol. Chem. 2000;275:3713-21.

9. Tasara T, Bielaszewska M, Nitzsche S,Karch H, Zweifel C, et al. Activatable Shiga toxin 2d (Stx2d) in STEC strains isolated from cattle and sheep at slaughter. Vet. Microbiol. 2008;131:199204 .

10. Wiley RG, Donohue-Rolfe A,Keusch GT. Axonally transported shigellacytotoxin is neuronotoxic. J. Neuropathol. Exp. Neurol. 1985;44:496-506.

11. World Health Organization. Program for control of diarrheal diseases. In Manual for Laboratory investigation of Acute Enteric Infections, CDD/93.3, rev.1. World Health Organization, Geneva, Switzerland. 1987; P.9-20.

12. Schmidt H, Geitz, Torr PI, Frosch M, Karch H, et al. Non-O157:H7 pathogenic shiga toxinproducing Escherichia coli: phenotypic and genetic profiling of virulence traits and evidence for clonality. J. Infect. Dis. 1999;179:115-23.

13. Bonnet $\mathrm{R}$, Souweine $\mathrm{B}$, Gauthier $\mathrm{G}$, Rich $\mathrm{C}$, Livrelli V, et al. Non-O157:H7 Stx2-producing Escherichia coli strains associated with sporadic cases of hemolytic-uremic syndrome in adults. J. Clin. Microbiol. 1998; 36:1777-80.

14. Karch HH, Huppertz J, Bockemithl H, Schmidt A, Schwarzkopf, et al. Shiga toxin-producing Escherichia coli infections in Germany. J. Food Prot. 1997; 60:1454-57.

15. Franke S, Gunzer F, Wieler LH, Baljer G, Karch H. Construction of recombinant Shiga-like toxinIIv(SLT-IIv) and its use in monitoring the SLT-IIv antibody status in pigs. Vet. Microbiol. 1995; 43:41-52.
16. Friedrch A, BielaszewskaM, Zhang WL, Pulz M, Kuczius T, et al. Escherichia coli harbouring Shiga toxin 2 gene variants: frequency anf association with clinical symtoms. J. Infect. Dis. 2002;185:74-84.

17. Talukder KA, Azmi IJ, Ahmed KA, Hossain MS, Kabir Y, Cravioto A, Sack DA, Nur-E-Kamal A. Activation of p53/ATM-dependent DNA damage signaling pathway by shiga toxin in mammalian cells.Microb. Pathog. 2012;52(6):311-17.

18. Sanyal, SC, Saraswathi B, Sharma P. Enteropathogenicity of Plesiomonasshigelloides. J. Med. Microbiol.1980;13:401-09.

19. Nur-E-Kamal A, Li TK, Zhang A, Qi H, Hars ES, Liu LF. Single-stranded DNA induces ataxia telangiectasia mutant (ATM)/p53-dependent DNA damage and apoptotic signals. J Biol Chem. 2003; 278:12475-81.

20. Singh SJ, Sanyal SC. Enterotoxicity of the socalled NAG vibrio. Ann. Soc. Belg. Med. Top. 1978; 58:133-40.

21. Fernandez A, Sninsky CA, O'Brien AD, et al. Purified Shigella enterotoxin does not alter intestinal motility. Infect. Immun. 1984; 43:47781.

22. Spira MW, Bradley sack R, Froehlich JL, Clench MH, Mathias JR. Simple adult rabbit model for Vibrio cholerae and enterotoxigenicEcherichia coli diarrhea. Infect. Immun. 1981; 32:739-47.

23. MacLeod DL, Gyles CL. Purification and characterization of an Escherichia coli. Infection and Immunity. 1990; 58:1232-39.

24. Elwell C, Chao K, Patel K, Dreyfus L. Escherichia coliCdtB mediates cytolethal distending toxin cell cycle arrest. Infect Immun. 2001; 69: 3418-22.

25. Aragon V, Chao K, Dreyfus LA. Effect of cytolethal distending toxin on F-actin assembly and cell division in Chinese hamster ovary cells. Infect. Immun. 1997; 65:3774-80.

26. O'Brien AD, Lively TA, Chen M, Rothman SW,Formal SB. Escherichia coli O157:H7 strains associated with haemorrhagic colitis in the United States produce aShigelladysenteriae1 (Shiga) like cytotoxin. Lancet.1983;1:702.

27. Riley LW. The epidemiologic, clinical and microbiological features of hemorrhagic colitis. Annu. Rev. Microbiol.1987;41:383-407.

28. Henry FJ, Udoy AS, Wanke CA,Aziz KM. Epidemiology of persistent diarrhea and etiologic agents in Mirzapur, Bangladesh. Acta Paediatr.1996;381:27-31.

29. Albert MJ, Faruque SM, Faruque AS, Neogi PK, Ansaruzzaman $\mathrm{M}$, et al. Controlled study of Escherichia coli diarrheal infections in 
Bangladesh children. J. Clin. Microbiol. 1995; 33:973-77.

30. Keenan KP, Sharpnack DD, Collins H, Formal $\mathrm{SB}$, O'Brien AD.Morphologic evaluation of the effects of Shiga toxin and E. coli Shiga-like toxin on the rabbit intestine. Am. J. Pathol. 1986;125:69.

31. Zajdowicz T. Epidemiologic and clinical aspects of shigellosis in American forces deployed to Saudi Arabia. South Med. J.1993;86:647-50.

32. Kowlessar M, Forbes GB. The febrile convulsion in shigellosis. N. Eng. J. Med.1958;1258:520-526.

33. Avital A, Maayan C, Goitein KL. Incidence of convulsions and encephalopathy in childhood Shigella infections. Clin. Pediatr. (Phila). 1982;21:645-48.

34. Richardson SE, Rotman TA, Jay V, Smith CR, Becker LE, et al. Experimental verocytotoxemia in rabbits. Infect. Immun.1992;60:4154-67.
35. Obata F, TohyamaK, Boney AD, Kolling GL, Keepers TR, et al. Shiga toxin 2 affects the central nervous system through receptor globotriaosyceramide localized to neurons. J. infect. Dis.2008;198:1398-1406.

36. Fontaine A, Arondel J, Sansonetti PJ. Role of Shiga toxin in the pathogenesis of bacillary dysentery, studied by using a Tox-mutant of Shigelladysenteriae 1. Infect. Immun.1988;56:3099-3109.

37. Karmali MA, Petric M, Lim C, Fleming PC, Arbus GS, et al. The association between hemolytic uremic syndrome and infection by Verotoxin-producing Escherichia coli.J. Infect. Dis. 1985;151:775-82.

38. TeshVL, O'Brien AD. The pathogenic mechanisms of Shiga toxin and the Shiga-like toxins. Mol. Microbiol. 1991;5:1817-22. 